\title{
Live Streaming: A New Platform for ESL Learning
}

\author{
Nurain Adila Abdul Samat1,2, Harwati Hashim ${ }^{2 *}$, Melor Md. Yunus ${ }^{2}$ \\ ${ }^{1}$ SK Taman Sri Muda, Shah Alam, Malaysia \\ ${ }^{2}$ Faculty of Education, Universiti Kebangsaan Malaysia, Bangi, Malaysia \\ Email: ^harwati@ukm.edu.my
}

How to cite this paper: Samat, N. A. A., Hashim, H., \& Yunus, M. Md. (2019). Live Streaming: A New Platform for ESL Learning. Creative Education, 10, 2899-2906. https://doi.org/10.4236/ce.2019.1012215

Received: October 21, 2019

Accepted: November 26, 2019

Published: November 29, 2019

Copyright (C) 2019 by author(s) and Scientific Research Publishing Inc. This work is licensed under the Creative Commons Attribution International License (CC BY 4.0).

http://creativecommons.org/licenses/by/4.0/ (c) (†) Open Access

\begin{abstract}
Research on the application of live streaming in ESL learning is still quite scarce among researchers especially in Malaysia. However, a number of studies on live streaming in the field of marketing and branding as well as the culture of live streaming are evolving rapidly. A lot of researches also have been done on games streaming. As live streaming has become more significant in all field, a study on the impacts of live streaming in the education field should become important, too. Therefore, this leads to the purpose of the study which is to explore the possibility of live streaming as a new platform for ESL learning. Since Gen $\mathrm{Z}$ requires teaching and learning process that suits their learning preference. Hence, live streaming serves as a good platform for them to indulge in the ESL learning process. A lot of reading has been done to give emphasis on the significance of the study. Live streaming will be helpful in ESL learning to keep pace with globalization, produce independent learners, provide authentic learning experiences as well as give rooms for real life communication and interactivity. The discussion of this study would hopefully shed lights to researcher to investigate further in this area.
\end{abstract}

\section{Keywords}

Live Streaming, ESL Learning, Gen Z, Globalization, Authentic Learning

\section{Introduction}

In today's world with the advancement of technology, system, applications and Internet, live streaming has become prominent day by day. Businessmen and traders are using live streaming as their marketing strategy in which it acts as a platform to increase their sales and expose their brands to a wide range of cus- 
tomers all over the world. High access to technology and the internet as well as the popularity of social media allows people to use live streaming for their personal use, sharing of information, communication, and many more. Nagy et al. (2018) mentioned the emergence of industrial revolution 4.0 acts as a booster to the culture of live streaming, too. The reason being is that it encourages people to use machines which are connected as a collaborative community and "interface" to communicate in a real-time way. This is why live streaming is currently one way of how industrial revolution 4.0 is being reflected among people around the world. By streaming live on the Internet, we connect with people and work collaboratively as well as experiencing events which occurred on the actual time it is occurring. This leads to a need to shift the education system especially in ESL learning (Hashim, Yunus, \& Embi, 2018; Hashim, Yunus, \& Hashim, 2019). English which is known as the language of globalization should be taught with a new approach to improve learning quality and also promote the new trends in technology which is live streaming. In Malaysia, the concept of $21^{\text {st }}$ century learning engages learners with technology and appoints them as "self-directed learners" to get them ready for life-long learning (Yusop, 2014; Hashim \& Yunus, 2010). There is a need to learn English by incorporating the element of technology at the same time (Yunus et al., 2010; Yunus, Salehi, \& Chenzi, 2012).

Educators nowadays need to keep up with learners' changing interests while learning. Teachers are deemed to know learners' characteristics, learning preference, and interest to provide the best learning experience. Feng \& Ots (2015) explained how content marketing is important to ensure that customers are committing to their brand. The same concept should be applied in our education system, too. Teachers should ensure that learning content is preferable to the learners to gain their attentiveness towards learning. Today's generation of learners is known as Generation Z. Singh and Dangmei (2016) described generation $\mathrm{Z}$ as those who were born in 1990's and raised in the 2000's where the world is equipped with laptops, smartphones, internet, networks and digital media. They are called the digital natives who know nothing but smartphones and social media and are defined by their use of technology (Giannetto, 2018).

In the context of a learner Dollot (2018) indicated that generation $\mathrm{Z}$ are learners who are unable to concentrate or memorize something due to the regular use of multi-tasking application. They are able to share information easily and communicate frequently as they use wide variety of communication devices or social media. Salleh, Mahbob and Baharudin (2017) portray Gen Z multitasking ability as such for instance, a student might read a textbook while listening to the iPod and also updating their social media status at the same time. As Generation $\mathrm{Z}$ is currently occupying the educational sector, more attention should be given in designing and delivering instruction that will suit their personality. However, the current education system in Malaysia provides little opportunities for Generation $\mathrm{Z}$ to explore learning according to their preferences. Much more should be done by the government to accommodate their needs. UNESCO (2013) found that urban schools in Malaysia are provided with better 
infrastructure and technology compared to rural schools which reflect insufficient of resources to support learning. Besides, most of the information and learning inputs for English language are given through textbooks, writing books and reference books. The latest English textbooks being used in lower level primary school nowadays is Super Minds from Cambridge University Press while for the lower level of secondary school is MacMillan's Pulse 2. In contrast, Jaleniauskiene \& Juceviciene (2015) indicated that a high exposure towards the Internet leads them to mostly preferred video watching instead of reading hardcopy media, books and manuals. This shows that schools had given less emphasis on the learner's preference and learning style. Hence, the purpose of this paper is to explore the possibility of live streaming as a new platform for ESL learning.

\section{What Is Live Streaming?}

Live streaming is a way of connecting with people around the world using internet and technology. Svart (2018) explained live streaming allows broadcasting of an event in the actual time it is happening on the internet plus the audience can watch it without the hassle to download the content first into the computer. Ojala (2019) elaborated live streaming as a process which uses the internet to send or stream live video and audio footage online; it can be watched live or later through past broadcasts. Chen, Freeman and Balakrishnan (2019) said live streaming requires a streamer who is broadcasting in real-time to viewers who can give comments on a chat channel. On the other hand, Scheibe, Fietkiewicz and Stock (2016) introduced a new term which is social live streaming services (SLSSs). They divided live streaming into 2 categories which are general live streaming services like Facebook live, YouTube live and Twitter's Periscope; and topic-specific live streaming service like Twitch for games or Picarto for art. The live streaming platform was originally started when YouTube explored the world of live video in 2013 and back at the time it was only available to high profile creators (BoxCast Team, 2019). However, things started to change when social media incite the use of live streaming among their users. For examples, Periscope for Twitter, Facebook Live for Facebook users and Instagram Live for Instagram.

\section{Why Live Streaming?}

\subsection{Keep Pace with Globalization}

One of the reasons why live streaming should be used as a platform for ESL learning is to keep pace with globalization. Nowadays, live streaming is on the rise and it has become the current trend. This is why education nowadays has shift from pedagogy to different approaches and currently educators should opt for education that suits the needs of the society (Chan, Embi, \& Hashim, 2019). More people especially Gen $\mathrm{Z}$ are showing interest in using live streaming for different purposes through their social media or other platform. Based on the survey conducted by Marketingcharts.com (2018) to a more than 1000 members 
of Gen $\mathrm{Z}$ in the US and the UK, the result found that their social media preferences are $41 \%$ for Instagram, $40 \%$ favored Snapchat and Facebook with 39\%. Likewise, Williams (2017) shared that $90 \%$ of generation $\mathrm{Z}$ was influenced with social media like Facebook, Instagram and Snapchat when they are making decisions. These are all social media which provides live streaming as one of the main features. It shows that live streaming has becomes parts of their daily lives. Globalization and rapid technological transformation has led to the concepts of a borderless world, liberalization of global information, and global learning. Technology in the new curriculum presents learners (future citizens) with global information and the means for global communication enabling them to become active global players. Live streaming enables learners to keep in touch with global citizens and global knowledge which at the same time promotes equal opportunity in education. Equal opportunity means every child in this world must be given the same right to education despite their differences in terms of gender, religion, socio-economic status, ethnicity or geographical conditions (Nordin, 2011). Hence, live streaming offers an opportunity to the learners to be part of the global citizens who are not being left behind despite of where you live or who you are.

\subsection{Independent Learning}

Live streaming is an activity that supports independent learning as it allows learners to use it on their own according to their preferable time. Research conducted by Couillault (2011) showed that providing ICT, technology and e-learning to the students could promote independent learning better compared to other strategies. Gill and Halim (2008) identifies independent learning as significant in developing learners who are able to manage their own learning goals. Live streaming gives infinite possibilities for the learner to explore the learning content as much as they want without any limitations. This is because live streaming not only creating independent learners but also producing an increasing number of independent educators who offer live streams for language learning (Chen et al., 2019). The Air Asia tagline which is "Now everyone can fly" can be applied in this situation too as by live streaming online "Now everyone can learn and teach". It gives learners a sense of autonomy which makes them feel in control over their own learning process. They have to make choices and choose what they want to learn from all the available information shared by the streamers online. They learn to differentiate what is good and what is bad based on their own thinking and judgement. These whole processes shape them to become good independent learners and at the same time supports the notion of 21st century learning in Malaysia (PAK21). The Ministry of Education in Malaysia aims to nurture students who are productive, skillful in using Information and Communication Technology plus being able to think critically (Ministry of Education, 2013). Zakaria, Di and Yunus (2017) explained in details that students are required to work collaboratively with people, connect with the world to learn and being a critical thinker in making decisions and solve problems. 
Hence, live streaming in teaching and learning supports the government vision of 21st century learning (PAK21) as it indulges technology to fortify the teaching and learning experience.

\subsection{Authentic Learning Experience}

The most effective way of learning a language is through authentic learning experience. Allowing the learners to be part of the society who speaks the language will give them much excitement. The opportunity to converse with the native speaker of the language also will open up more learning possibilities compared to traditional way of learning the language in the classroom. According to Arnett et al. (2019) live streaming is very useful as it permits connection with people around the world and learners can engage in real-time shared learning experiences. Furthermore, it is authentic because audiences may associate with the streamer's attitudes and values before forming a stream community (Zhang, 2017). The element of 'liveness' delivers authentic experience to the audience as the streamers show spontaneous interaction without premeditations (Yan, 2016). A research conducted in China by Lu et al. (2018) shows how the Chinese are taking advantages on authentic learning experience that a live streaming could offer. They acquire new knowledge by watching lectures where the streamer talked about the topic, showing the procedure or essential information using slides or other media, and answered questions from viewers. Another research by Chen et al. (2019) portrays how a language learner learns pronunciation with the native language streamer online. The viewers sent recordings of their word or sentence they pronounced then the streamer corrected the pronunciation. After that, the viewers attempted the pronunciation again and looked for additional feedback through the comment sections. The learner's responded that it was a very good alternative as they learn the correct way of saying it from the native speaker of the language themselves. Hence, Malaysian learners should be exposed with live streaming in education too so that they are able to gain authentic experience while interacting with another ESL learners or native speakers of English. They could ask questions to solve language learning problems, clarify any confusion, sharing ideas and information as well as practice conversing in natural setting of the language.

\subsection{Communication and Interactivity}

A good language learner is an individual who is able to communicate and interact using the language. It is the standard that we set to see whether you are able to apply everything you have learnt to produce language proficiently. The main goal of each ESL learner is to be proficient in English. In Malaysia, the Malaysia Education Blueprint 2013-2025 aims to ensure that pupils are proficient in using both Malay and English languages upon leaving the primary and secondary education (MOE, 2013). A lot has to be done in school to achieve the set vision. Live streaming is a platform where teachers and learners would be able to communicate and interact using the language. In today's globalization era, the 
emergence of technology requires younger generations to have excellent communication skill (Yunus, Hashim, \& Hashim, 2019). When an audience watches a live stream video, he or she will not only interact with the streamer but also other viewers in the stream community. It leads towards a group communication in a virtual space where everyone could share their opinions by giving comments to one another. On the other hand, how a streamer responds during the live stream serves as a good practice to improve his or her communication skill. In the context of ESL learners, Chen et al. (2019) said live streaming made language learning more interactive as it brings people closer through personal interactions, emotion expression and getting to know more about other viewers' lives. As live streaming shows event which happens at the real time, communication and interaction occurs naturally alongside the event taking place on that particular time. For instance, a current trend of live streaming in South Korea is to show people that you are studying or doing revision online (Park, 2018). A man had showcased himself preparing for a state-run tax accountant's exam. Although the man did not say anything in the video, it had garnered so much attention from the viewers as they are giving words of encouragement to the streamer, cheering him up before the examinations, leaving some inspiring quotes and also sharing some good tips on how to tackle the examinations. This clearly shows how interactive live streaming can be among those who are involved.

\section{Conclusion and Implications}

The rapid growth of live streaming culture among younger generations could really act as a platform for ESL learners all over the world to make use of it in their English learning process. As they are very familiar with what and how to go about live streaming in social media, it should come in handy if they are to employ live streaming techniques while studying. High popularity of live streaming in many aspects of life such as information sharing, demonstrating authentic experience, promoting brands and business shows that live streaming is also possible to be used for the purpose of educating learners all over the world. The advancement of technology, gadgets and high speed of internet are some of the factors which could assist in providing better experience during live streaming. In the context of ESL learning, interactions and communication in the language will become more interesting and genuine as live streaming engages learners with actual learning experience. Thus, all discussions and elaboration above made it possible for live streaming to become a new platform for ESL learning. More researchers should show some interest in exploring this field as people have started to grow a deep interest in live streaming day by day.

\section{Acknowledgements}

The authors disclose that this work was supported by Universiti Kebangsaan Malaysia, Grant number: KRA-2018-044 and PP-FPEND-2019. 


\section{Conflicts of Interest}

The authors declare no conflicts of interest regarding the publication of this paper.

\section{References}

Arnett, L., Netzorg, R., Chaintreau, A., \& Wu, E. (2019). Cross-Platform Interactions and Popularity in the Live-Streaming Community. In Extended Abstracts of the $2019 \mathrm{CHI}$ Conference (Paper No. LBW1211). New York: ACM. https://doi.org/10.1145/3290607.3312900

BoxCast Team (2019). State of Live Streaming in 2019: Last 5 Years + Next 5 Years. https://www.boxcast.com/blog/state-of-live-streaming-in-2019-last-5-years-next-5-yea $\underline{\text { rs }}$

Chan, C., Embi, M., \& Hashim, H. (2019). Primary School Teachers' Readiness towards Heutagogy and Peeragogy. Asian Education Studies, 4, 11-21. https://doi.org/10.20849/aes.v4i1.602

Chen, D. L., Freeman, D., \& Balakrishnan, R. (2019). Integrating Multimedia Tools to Enrich Interactions in Live Streaming for Language Learning. In Proceedings of the 2019 CHI Conference on Human Factors in Computing Systems (Paper No. 438). New York: ACM. https://doi.org/10.1145/3290605.3300668

Couillault, V. R. (2011). Expectations and Experiences of Independent Learning in Two New Zealand Secondary Schools. Thesis of Master of Educational Leadership and Management, Auckland: Unitec Institute of Technology.

Dollot, A. (2018). The Characteristic of Generation Z. E-Mentor, 2, 44-50. https://doi.org/10.15219/em74.1351

Feng, S., \& Ots, M. (2015). Content Marketing: A Review of Academic Literature and Future Research Directions. In Europe Media Management Association.

Giannetto, J. (2018). How to Make Gen Z Love Your City. https://envisionitagency.com/blog/2018/11/6-ways-to-make-gen-z-love-your-city

Gill, G. K., \& Halim, N. A. (2008). The "I" in Independent Learning: The Rise of Self-Managing Learners. In AARE 2007 International Education Research Conference.

Hashim, H. U., Yunus, M. M., \& Hashim, H. (2019). 3-Minutes Pitching with Flip Grid: An Antidote of Innovation for Speaking Anxiety. International Journal of Innovative Technology and Exploring Engineering, 8, 1798-1801.

Hashim, H., \& Yunus, M. M. (2010). Learning via ICT: “Tell Me More”. International Journal of Learning, 17, 211-224.

Hashim, H., Yunus, M. M., \& Embi, M. A. (2018). Factors Influencing Polytechnic English as Second Language (ESL) Learners' Attitude and Intention for Using Mobile Learning. Asian ESP Journal, 14, 195-208.

Jaleniauskiene, E., \& Juceviciene, P. (2015). Reconsidering University Educational Environment for the Learners of Generation Z. Socscie Social Sciences, 88, 88. https://doi.org/10.5755/j01.ss.88.2.12737

Lu, Z., Xia, H., Heo, S., \& Wigdor, D. (2018). You Watch, You Give, and You Engage: A Study of Live Streaming Practices in China. In The ACM 2018 CHI Conference on Human Factors in Computing Systems (pp. 1-14). New York: ACM. https://doi.org/10.1145/3173574.3174040

Marketingcharts.com (2018). Most Gen z Shoppers Say They Often Discover Products on Social Media. 
https://www.marketingcharts.com/industries/retail-and-e-commerce-105587

Ministry of Education (2013). Malaysia Education Blueprint 2013-2025. Kuala Lumpur: Kementerian Pendidikan Malaysia.

Nagy, J., Olah, J., Erdei, E., Mate, D., \& Popp, J. (2018). The Role and Impact of Industry 4.0 and the Internet of Things on the Business Strategy of the Value Chain: The Case of Hungary. Sustainability, 10, 3491-3516. https://doi.org/10.3390/su10103491

Nordin, A. B. (2011). Equity: Problems in the Implementation of Educational Policies and Reforms in Malaysia. Journal of Education, 6, 115-127.

Ojala, A. (2019). The Effects of the Video Gaming Industry on Finnish Travelers. Degree Programme in Hospitality, Tourism and Experience Management, Helsinki: University of Applied Sciences.

Park, J. Y. (2018). Why Do Koreans Watch Others Studying Alone on YouTube? https://www.asiaone.com/asia/why-do-koreans-watch-others-studying-alone-youtube

Salleh, M. S. M., Mahbob, N. N., \& Baharudin, N. S. (2017). Overview of “Generation Z" Behavioural Characteristic and Its Effect towards Hostel Facility. International Journal of Real Estate Studies, 11, 59-67.

Scheibe, K., Fietkiewicz, K. J., \& Stock, W. G. (2016). Information Behavior on Social Live Streaming Services. Journal of Information Science Theory and Practice, 4, 6-20. https://doi.org/10.1633/JISTaP.2016.4.2.1

Singh, A. P., \& Dangmei, J. (2016). Understanding the Generation Z: The Future Workforce. South-Asian Journal of Multidisciplinary Studies, 3, 1-5.

Svart, A. (2018). The Use of Live Streaming in Marketing. Bachelor's Thesis Programme International Business Administration, Tallinn: Tallinn University of Technology.

United Nations Educational Scientific and Cultural Organization (UNESCO) (2013). Malaysia Education Policy Review: Abridged Report. Kuala Lumpur: Ministry of Education Malaysia.

Williams, R. (2017). Expedia: 90\% of Gen Z Travelers Influenced by Social Media. https://www.mobilemarketer.com/news/expedia-90-of-gen-z-travelers-influenced-by-s ocial-media/505987

Yan, X. F. (2016). Exploring Online Live Streaming in Communication “Scene" Perspective. Press Circles, 15, 51-54.

Yunus, M. M., Hashim, H., Embi, M. A., \& Lubis, M. A. (2010). The Utilization of ICT in the Teaching and Learning of English: "Tell Me More". Procedia-Social and Behavioral Sciences, 9, 685-691. https://doi.org/10.1016/j.sbspro.2010.12.218

Yunus, M. M., Salehi, H., \& Chenzi, C. (2012). Integrating Social Networking Tools into ESL Writing Classroom: Strengths and Weaknesses. English Language Teaching, 5, 42-48. https://doi.org/10.5539/elt.v5n8p42

Yunus, M. M., Umiera Hashim, H., \& Hashim, H. (2019). Massive Open Online Courses: En Route to Communication Skills Acquisition. Arab World English Journal (AWEJ) Special Issue on CALL, No. 5, 98-109. https://doi.org/10.24093/awej/call5.8

Yusup, H. (2014). 21st Century Education: Are We Heading the Right Direction of Improving Teaching and Learning as Needed by Educational Programme. Kuala Lumpur: Asia e University.

Zakaria, A. A., Di, L. Y., \& Yunus, M. M. (2017). 21st Century Education in Teaching English as a Second Language (ESL) in Malaysia. Prosiding Seminar Serantau, 8, 382-390

Zhang, Q. (2017). Live Streaming and Its Audiences in China Making Sense of Authenticity. Media@LSE Working Paper Series. London: Media@LSE. 